\title{
15-year groin hernia trends in Australia: the era of minimally invasive surgeons
}

Running title: Australia trends of groin hernia repairs

\author{
Jasmina Kevric MBBS BMedSci MPH, Nathan Papa MBBS MEpi, Sumeet Toshniwal \\ MBBS MS FRACS, Marlon Perera MBBS BMedSci
}

Keywords: laparoscopic hernia repair, inguinal hernia, Australian trend hernia repair

Corresponding author:

Dr Jasmina Kevric

Department of General Surgery, Monash Health

Clayton, Victoria 3175

Correspondence: kevricj@gmail.com

Disclosures: There are no disclosures. The corresponding author is not a recipient of a scholarship. NP is the recipient of a research scholarship provided by the Victorian Cancer Council. MP is the recipient of a research scholarship provided by the Royal Australasian College of Surgeons.

Number of figures: 4

Number of tables: 2

This is the author manuscript accepted for publication and has undergone full peer review but has not been through the copyediting, typesetting, pagination and proofreading process, which may lead to differences between this version and the Version of Record. Please cite this article as doi: 10.1111/ans.13899

This article is protected by copyright. All rights reserved. 
Word count (incl. references): 2241

\section{Abstract}

\section{Introduction}

Groin hernia repairs (GHRs) are among the commonest general surgical procedures in the Western population. The introduction of minimally-invasive surgery has prompted the development of laparoscopic totally-extraperitoneal and transabdominal pre-peritoneal hernia repairs. We aimed to determine the hernia treatment trends in Australia over the last 15 years.

\section{Methods}

Using Medicare Benefit Scheme (MBS) data, we categorized the number of laparoscopic and open hernia repairs between 2000 and 2015 in Australia. Population data was collected from the Australian Bureau of statistics. Hernia repair rates were standardised by age, gender and location.

\section{Results}

During the study period, a total of 324,618 GHRs on adult patients were performed in Australia, $43 \%$ by a laparoscopic method. While there was a slight yearly increase in overall total GHRs performed, laparoscopic surgeries increased by 3.1 per 100,000

This article is protected by copyright. All rights reserved. 
population every year ( $95 \% \mathrm{Cl}: 2.9-3.3)$ while open surgeries declined yearly by 2.6 per 100,000 population ( $95 \% \mathrm{Cl}: 2.4-2.8)$. From the available data, there appears to be a crossover point in 2011/2012 where the laparoscopic hernia repair became more frequent. Considerable state and gender-based trends exist.

\section{Conclusions}

The use of laparoscopic groin hernia repairs has increased considerably over the last 15 years. Despite the increased use, significant state-based and gender discrepancies were observed. Our data offers insight to the public sector and the respective healthcare related expenditures pertaining to LHR. Abstract word count: 223

This article is protected by copyright. All rights reserved. 


\section{Introduction}

Groin hernia repairs (GHRs) are among the most common surgical procedures performed in the Western world, accounting for more than 20 million repairs globally per annum (1). With the ageing Australian population, both elective and emergency GHRs are increasing. Further, this may be attributed to the increased diagnosis of asymptomatic GHs based on radiological scanning (2).

In present clinical practice, operative techniques include laparoscopic and open repairs, establishing a tension free mesh repair as the gold standard practice of care (1). The advancement in laparoscopy has had an impact on the incidence of associated complications over the last decade, with many studies indicating a reduction in post-operative pain and length of hospital stay (3). Minimally-invasive techniques include laparoscopic totally extra-peritoneal (TEP) and trans-abdominal preperitoneal (TAPP) approaches. Despite the predominant use of TEP repairs, comparative studies highlight similar post-operative pain scores, hospital length of stay and rates of recurrence between the two laparoscopic hernia repairs (LHRs) (4). Standard polypropylene mesh is still the preferred choice for most repairs.

Although studies have indicated considerable advantages of laparoscopic compared to open repairs, the steep learning curve associated with TEP and TAPP require considerable surgical expertise to maintain acceptable outcomes (5).

Operative times are longer compared to open repairs, however this improves with experience. There are also higher operating costs associated with LHR, which may

This article is protected by copyright. All rights reserved. 
impact on service delivery of individual hospitals (6). In this study we aim to determine the trends over the past 15 years in Australia for GHs.

\section{Methods}

\section{Data extraction}

From July 2001 to June 2015, data regarding the total number of hernia surgeries performed was obtained from the Medicare Australia website (7). Data were stratified by year, age, gender and state. Chronological data were extracted in financial year format, hence we assigned the year as the second half of the time period, e.g. 2001/2002 was assigned the year 2002. We excluded surgeries performed on paediatric patients aged under 15 years. LHRs were identified by Medicare Benefit Schedule (MBS) code 30609, "Femoral or inguinal hernia, laparoscopic repair of, not being a service associated with a service to which item 30614 applies". Open GHRs were identified by MBS billing codes 30612 and 30614, "Femoral of inguinal hernia or infantile hydrocele, repair of, not being a service to which item 30403 or 30615 applies, on a person 10 years of age or over".

Corresponding population data was extracted from the Australian Bureau of Statistics (ABS) for 2002 to 2014 (8) and for 2015 (9). The population figures obtained were from the ABS estimates at $30^{\text {th }}$ June of the corresponding year, in accordance with the Medicare data.

This article is protected by copyright. All rights reserved. 


\section{Statistical analysis}

We calculated incidence rates per 100,000 people using a denominator specific to the study population. For example, the sex-specific incidence of open hernia repair for males in 2003 was calculated as the total number of open hernia surgeries in $2002 / 2003$ multiplied by 100,000 and divided by the estimated Australian male population on $30^{\text {th }}$ June 2003 . Subsequently, we directly standardised these rates using the age and sex specific populations in 2002 as the reference. This standardisation was not performed for the elderly patient subgroup analysis. The territories were not included in the state-based analysis as the number of operations performed per year is low and differences are likely due to a small number of surgeons. To evaluate the growth or decline in a particular surgery we used univariable linear regression with year as the independent variable. Data analysis was performed using Stata v.12.0 SE (College Station, TX, USA).

\section{$\underline{\text { Results }}$}

From July 2001 to June 2015, a total of 324,618 GHRs on adult patients were performed in Australia, $43 \%$ by a laparoscopic method (Table 1). Females (30\%) and elderly patients (aged 75 years and over) (32\%) were less likely to be treated by this method. There were also regional differences noted, with Victorian patients also less likely to be treated laparoscopically (31\%).

This article is protected by copyright. All rights reserved. 
While there was a slight yearly increase in overall total GHRs performed, we observed a marked shift in the surgical approach used over the study period. Incidence of laparoscopic surgeries increased by 3.1 per 100,000 of population every year (95\% Cl: $2.9-3.3)$ while open surgeries declined yearly by 2.6 per 100,000 of population (95\% Cl: $2.4-2.6$ ) (Table 2). From the available data, there appears to be a crossover point in 2011/2012 where the LHRs became more frequent (Figure 1).

Female patients overall had a lower incidence of hernia surgery but were more likely to have that repair done via an open incision.

Regional differences in the mix of approach were noted (Figure 2). Surgeons in NSW and Queensland now perform the majority of operations laparoscopically, there is parity in SA and WA whereas in Victoria and Tasmania the open approach is still favoured. In Victoria, the absolute yearly decline in open and commensurate rise in LHRs is similar to other states, the lack of crossover reflecting a higher open surgery proportion in 2002. In Tasmania, the open method is still trending upwards. There were regional differences observed when examining female patients only. Only from 2014 are female NSW and Queensland patients as likely to receive their surgery laparoscopically as open whereas differences in approach (favouring open) remain in the other states (Figure 3).

Elderly patients aged 75 and over were relatively more likely to have hernia surgery, however there was downward trend for open surgeries and no crossover

This article is protected by copyright. All rights reserved. 
point observed where open surgery became less favoured as there is for younger patients (Figure 4).

\section{Discussion}

GHR remains as among the commonest general surgical procedures in the western population. The introduction of minimally-invasive surgery has prompted the development of TEP and TAPP techniques. The current study highlights the continuously increasing uptake in LHR in all states among all age groups for surgeries that use MBS claims. With this growing burden of LHRs, the implications on healthcare related expenditure must be taken into consideration.

The findings of the current study highlight the wide spread uptake of LHRs in Australia. While the overall standardised rates of GHR remain relatively stable, a considerable increase in the proportion of LHRs was observed. Interestingly, significant state-based discrepancies were observed, with NSW and Queensland exhibiting preferential use of LHR from 2009 onwards. Furthermore, the current data highlights the limited uptake in LHRs in females and elderly. This may be related to older patients having reduced myocardial and pulmonary functions which may be further compromised by pneumoperitoneum (10). Similarly, in the female population, it has been postulated that the low uptake may be related to the difficulty in diagnosing GHs given that the differential for groin pain in women is much more robust compared to men (11). Furthermore, the open approach may be

This article is protected by copyright. All rights reserved. 
relatively simple compared to LHR and the costs may not outweigh the advantages of a LHR in this group of patients.

Over the past 15 years, Australia appears to have had considerably higher uptake in LHR compared to global figures. In the UK between 2009 and 2012, while the utilization of TEP and TAPP had increased by $40 \%$, its use still remains relatively low $(23 \%)$ compared to open repairs (12). Similarly in Wales, the uptake of LHRs also remains low, with only $15 \%$ of surgeons surveyed regularly performing LHRs (13). Another survey performed in Turkey showed that $88.9 \%$ of the surgeons preferred open repair (14). Three consecutive surveys over three different periods showed no significant increase in uptake of LHR in Ankara (9.1\% (1997), 16.1\% (2001) and 11.1\% (2007)). Similar findings were seen in Pakistan where $71 \%$ of surgeons did not recommend the laparoscopic approach for inguinal hernia repairs (15). It is likely that the financial burden associated with these hernias and limited operating experience for surgeons contribute to the slower change of trend compared to Australia.

The Australian shift from open to LHR has significant implications on health economics. Recent studies have shown that operating and community costs for LHR are significantly increased compared to open repairs (16). Factors influencing costs associated with LHRs include the number of laparoscopic procedures performed per annum and the experience of the operating surgeon, the rates of hernia recurrence, serious complications and persistent pain (17). A recent study conducted in the UK

This article is protected by copyright. All rights reserved. 
showed that reusable equipment for laparoscopic surgery costs about $£ 170$ per procedure compared with disposable equipment, which costs about $£ 790$ per procedure (18). Similarly, Hynes et al (19) showed that LHR amounts to an average of $\$ 638$ more compared to open surgical techniques in North America. However, Jacobs et al (20) showed that reimbursement in an ambulatory surgery centre is more cost effective for LHR than for open repair and can be utilised by hospital institutions as a cost saving method. The economic impact of the shift to laparoscopic surgery in the Australian population is yet to be determined and would be a worthwhile avenue for further research.

There are several limitations to the current study. Firstly, there are inherent limitations with the used of MBS-based billing data. Such data requires the accurate billing by surgeons and administrators associated with each respective case. Despite these concerns, MBS-based data has been validated for use in the setting of various procedures (21). Further, data on billings from public sector was not available for analysis and may provide useful information for healthcare administrators. The data included reflects only surgeries claimed for MBS and therefore does not include all surgeries performed in Australia. Additionally, the MBS data does not differentiate between sporadic unilateral and recurrent or bilateral hernia repairs. Data inclusion for obstructed hernias was not suitable for inclusion for analysis as MBS coding does not specifically specify technique whether open or laparoscopic.

This article is protected by copyright. All rights reserved. 


\section{Conclusions}

In the current era of minimally-invasive surgery, there has been a widespread uptake in the use of LHR within the Australian private healthcare sector over the last 15 years. Despite the increased use, significant state-based and gender discrepancies were observed. Our data offers insight to the public sector and the respective healthcare related expenditures pertaining to LHR.

This article is protected by copyright. All rights reserved. 


\section{References}

1. Kulacoglu H. Current options in inguinal hernia repair in adult patients. Hippokratia. 2011;15(3):223-31.

2. Robinson A, Light D, Kasim A, Nice C. A systematic review and metaanalysis of the role of radiology in the diagnosis of occult inguinal hernia. Surgical endoscopy. 2013;27(1):11-8.

3. Langeveld H, Van't Riet M, Weidema W, Stassen L, Steyerberg E, Lange J, et al. Total extraperitoneal inguinal hernia repair compared with Lichtenstein (the LEVEL-Trial): a randomised controlled trial. Annals of surgery. 2010;251(5):819-24.

4. Krishna A, Misra M, Bansal V, Kumar S, Rajeshwari S, Chabra A. Laparoscopic inguinal hernia repair: transabdominal preperitoneal (TAPP) versus totally extraperitoneal (TEP) approach: a prospective randomised controlled trial. Surgical endoscopy. 2012;26(3):639-49.

5. Cheah W, So J, Lomanto D. Endoscopic extraperitoneal inguinal hernia repair: a serioes of 182 repairs. Singapore medical journal. 2004;45:267-70.

6. Kuhry E, Van Veen R, Langeveld H, Steyerberg E, Jeekel J, Bonjer H. Open or endoscopic total extraperitoneal inguinal hernia repair? A systematic review. Surgical endoscopy. 2007;21(2):161-6.

7. Australian Medicare Item Reports 2016, Australian Government [Available from: http://medicarestatistics.humanservices.gov.au.

8. Australian Bureau of statistics 2015, table generated 1 May 2016 Estimated resident population by age and sex, Regions of Australia (ASGS 2011), 2001 to 2014, cat. no. 3235.0 Population by Age and Sex, Regions of Australia, 2014 [Available from:

http://www.abs.gov.au/AUSSTATS/abs@.nsf/DetailsPage/3235.02014.

9. Australian Bureau of Statistics 2016, table generated 1 May 2016 using Quarterly Population Estimates (ERP), by State/Territory, Sex and Age, cat. no. 3101.0 Australian Demographic Statistics, Sep 2015 [Available from: http://www.abs.gov.au/AUSSTATS/abs@.nsf/DetailsPage/3101.0Sep\%202015? 10. Saber A, Elgamal M, Mancl T, Norman E, Boros M. Advanced age: is it an indication or contraindication for laparoscopic ventral hernia repair? Journal of the society of laparoendoscopic surgeons. 2011;12(1):46.

11. Ashfaq A, McGhan L, Chapital A, Harold K, Johnson D. Inguinal hernia repair in women: is the laparoscopic approach superior? Hernia.

2014;18(3):369-73.

12. Zendejas B, Ramirez T, Jones T, Kuchena A, Martinez J, Ali S, et al. Trends in the utilisation of inguinal hernia repair techniques: a population-based study. Americal Journal of Surgery. 2012;203(3):317.

13. Sanjay P, Woodward A. A survey of inguinal hernia repair in Wales with special emphasis on laparoscopic repair. Hernia. 2007;11(5):403-7. 
14. Kulacoglu H, Ozmen M, Oruc M, Kama N. Laparoscopic herniorrhaphy: preference rate among surgeons in Ankara, Turkey. East African medical journal. 2001;78(4):216-19.

15. Shamim S, Jaffary S, Faruqui N, Hameed K, Shamim M. Trends in management of inguinal hernia in Karachi, Pakistan: a survey of practice patterns. Singapore medical journal. 2006;47(6):512-7.

16. McCormack K, Wake B, Perez J, Fraser C, Cook J, McIntosh E, et al. Laparoscopic surgery for inguinal hernia repair: systematic review of effectiveness and economic evaluation. Health technology assessment. 2005;9(14):1-203.

17. Guidance on the use of laparoscopic surgery for inguinal hernia. NICE Technology Appraisal Guidance No. 18. London: National Institute for Clinical Excellence2001.

18. McKinlay R, Park A. Laparoscopic ventral hernia repair: a more effective alternative to conventional repair of recurrent incisional hernia. Journal of gastroenterology surgery. 2004;8:670-4.

19. Haynes D, Stroupe K, Luo P, Giobbe-Hurder A, Reda D, Kraft M, et al. Cost effectiveness of laparoscopic versus open mesh hernia operation: results of a Department of Veterans Affairs randomised clinical trial. Journal of Americal College of Surgery. 2006;203(4):447-57.

20. Jacobs V, Morrison J. Comparison of institutional costs for laparoscopic peritoneal inguinal hernia versus open repair and its reimbursement in an ambulatory surgery. Surgical laparoscopy endoscopy and percutaneous techniques. 2008;18:70-4.

21. Perera EG, N, Perera M, Sinclair R. Validating the use of Medicare Australia billing data to examine trends in skin cancer Research 2015;4:1341. 
Table 1. Breakdown of open and laparoscopic hernia repairs by state, gender, and age. The numbers in parentheses are the open/laparoscopic split within the column and according to geographic location.

\begin{tabular}{|c|c|c|c|c|c|}
\hline State & Total & Gender & & Age & \\
\hline & & Male & Female & 15 to 74 & $\geq 75$ \\
\hline Overall & $184253(57)$ & 157993 & $26260(70)$ & 154399 & 29854 (68) \\
\hline & & $(55)$ & & $(55)$ & \\
\hline ap & $140365(43)$ & 129095 & $11270(30)$ & 126481 & $13884(32)$ \\
\hline & & $(45)$ & & $(45)$ & \\
\hline NSW & $51801(49)$ & $44340(48)$ & $7461(64)$ & $43207(48)$ & $8594(61)$ \\
\hline ap & 52927 (51) & $48693(52)$ & $4234(36)$ & $47442(52)$ & 5485 (39) \\
\hline Victoria & $50372(69)$ & $43415(67)$ & 6957 (81) & $41690(67)$ & 8682 (79) \\
\hline & $22951(31)$ & 21269 (33) & $1682(19)$ & $20650(33)$ & 2301 (21) \\
\hline Queensland & $35308(49)$ & $29975(47)$ & $5333(64)$ & $29633(47)$ & $5675(62)$ \\
\hline & $36411(51)$ & $33461(53)$ & $2950(36)$ & $32873(53)$ & $3538(38)$ \\
\hline Open & $22156(65)$ & $19056(64)$ & 3100 (72) & $19295(64)$ & $2861(72)$ \\
\hline & $11863(35)$ & $10636(36)$ & 1227 (28) & $10776(36)$ & 1087 (28) \\
\hline Open & $14622(60)$ & $12547(58)$ & $2075(74)$ & $11910(58)$ & $2712(74)$ \\
\hline & $9712(40)$ & $8988(42)$ & 724 (26) & $8760(42)$ & $952(26)$ \\
\hline Tasmania $=$ Open & $5408(58)$ & $4624(55)$ & $784(74)$ & $4551(56)$ & $857(68)$ \\
\hline & $3970(42)$ & $3698(45)$ & $272(26)$ & $3570(44)$ & $400(32)$ \\
\hline Open & 3557 (69) & 3135 (67) & 422 (84) & 3122 (67) & $435(85)$ \\
\hline
\end{tabular}




\begin{tabular}{|lllllll|}
\hline & Lap & $1591(31)$ & $1513(33)$ & $78(16)$ & $1517(33)$ & $74(15)$ \\
ACT & Open & $1029(52)$ & $901(52)$ & $128(55)$ & $991(53)$ & $38(45)$ \\
& Lap & $940(48)$ & $837(48)$ & $103(45)$ & $893(47)$ & $47(55)$ \\
\hline
\end{tabular}

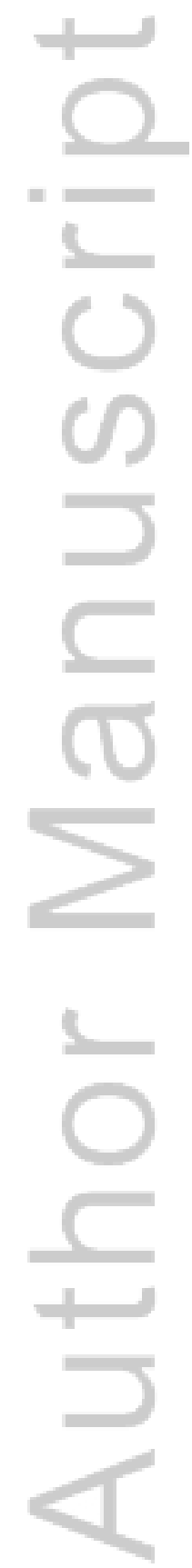

This article is protected by copyright. All rights reserved. 
Table 2. Yearly change in hernia repair surgeries performed per 100,000 of population, estimated by univariable linear regression, (95\% confidence interval in brackets).

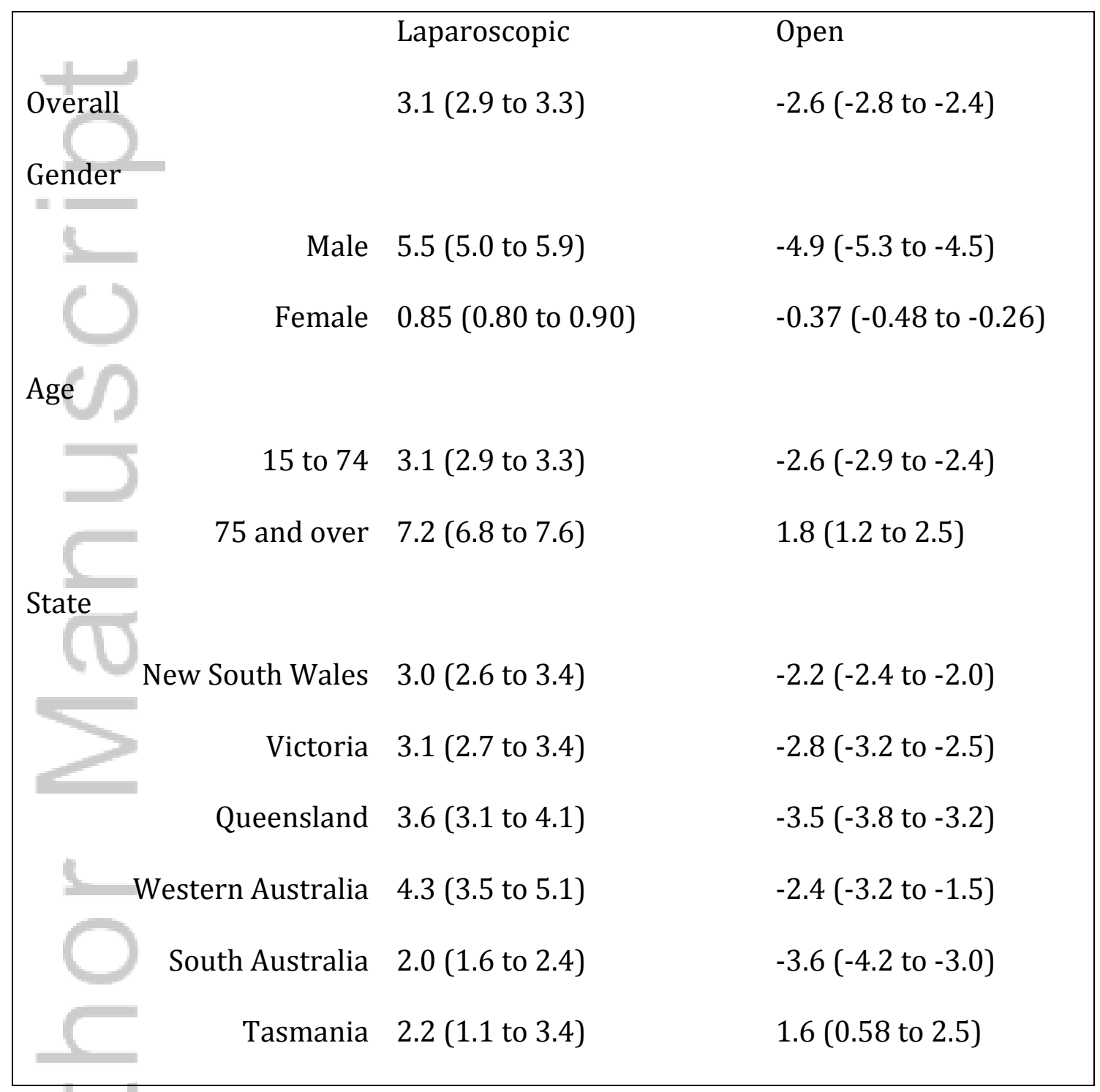

This article is protected by copyright. All rights reserved. 

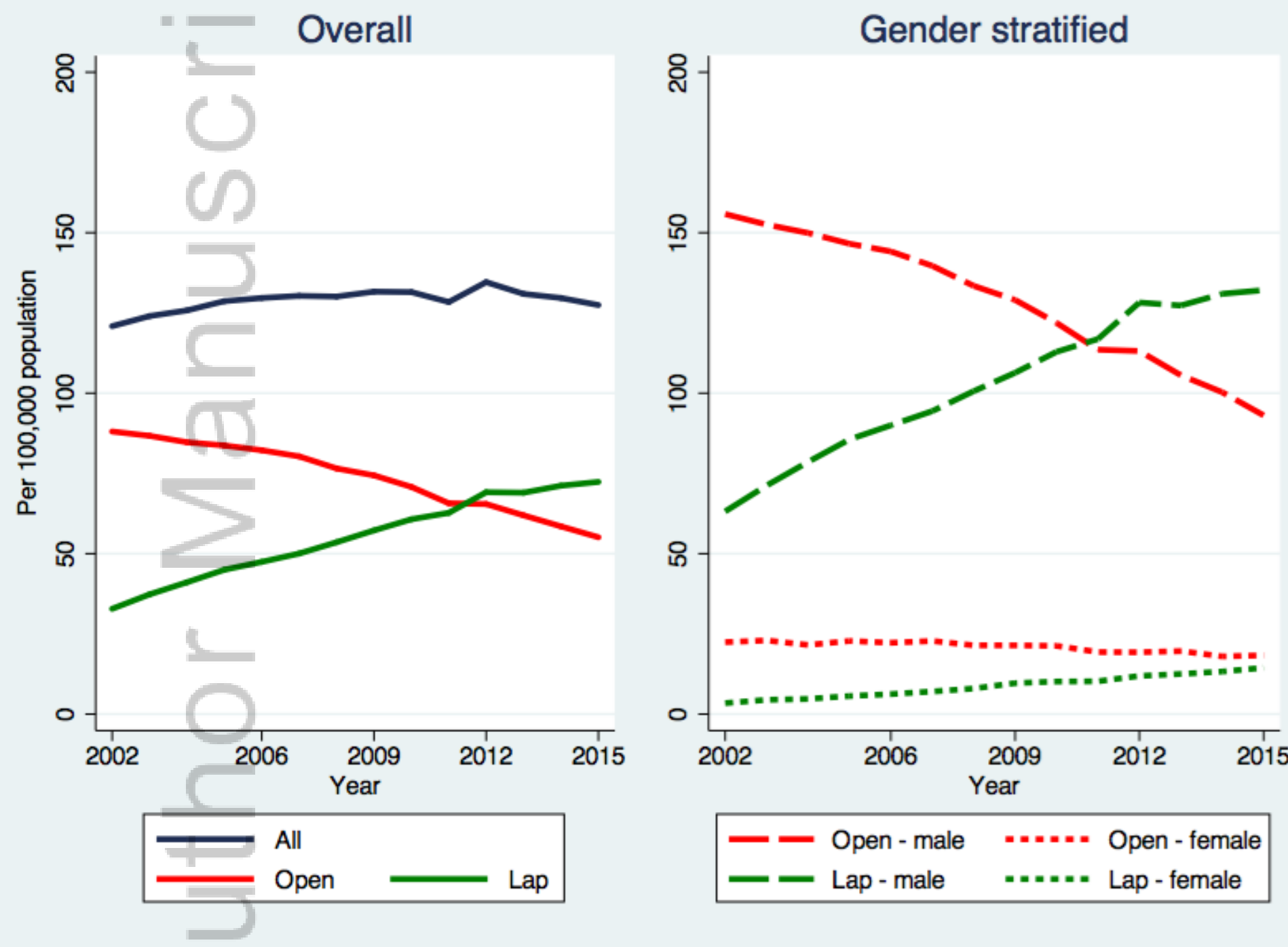

Figure 1. Yearly incidence of hernia surgeries performed, split by surgical approach and stratified by gender..tif 

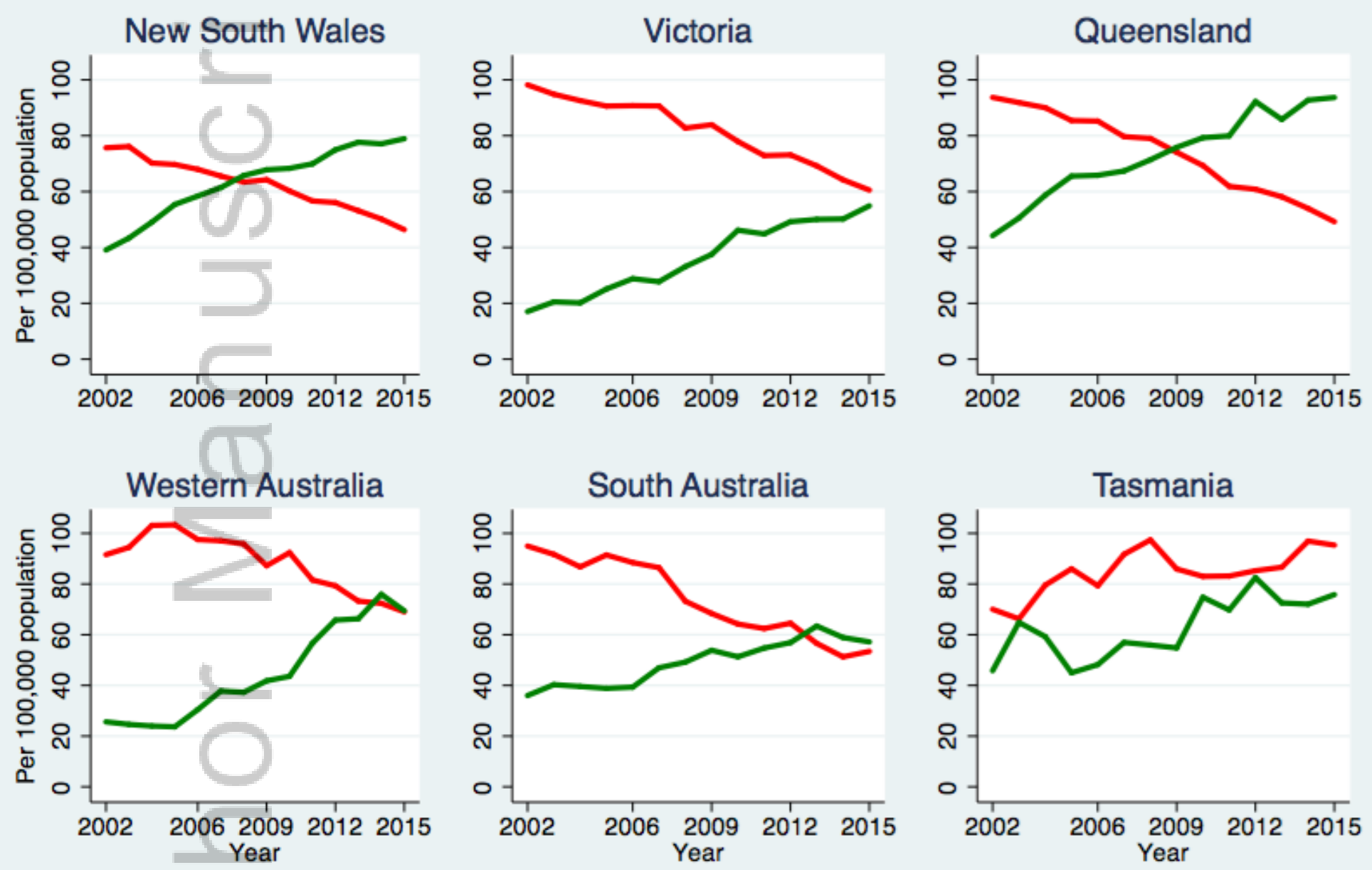

\section{Open}

\section{Laparoscopic}

Figure 2. Yearly incidence of hernia surgeries performed, split by surgical approach and stratified by state..tif 

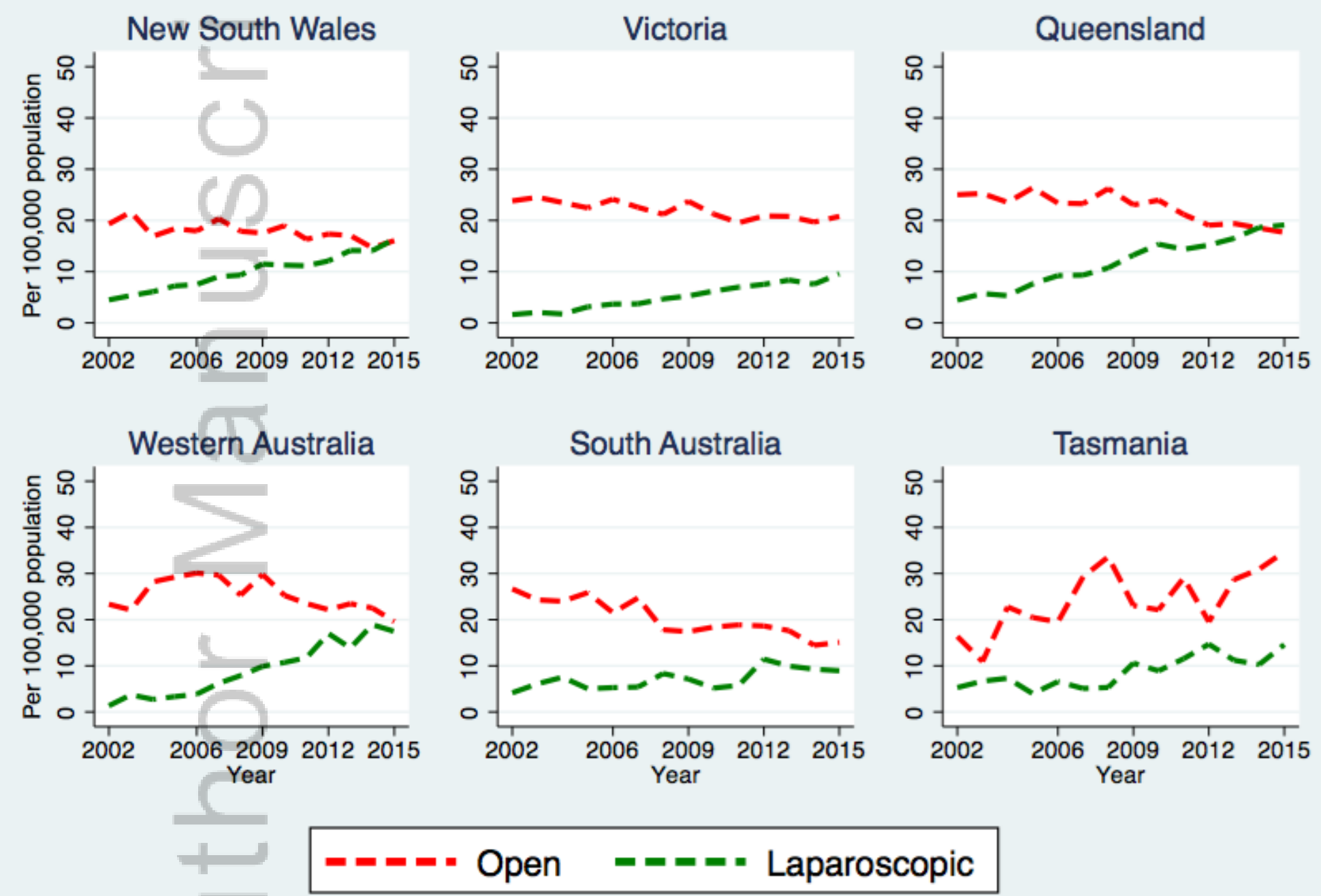

\section{Female patients only}

Figure 3. For female patients only, yearly incidence of hernia surgeries performed, split by surgical approach and stratified by state..tif 


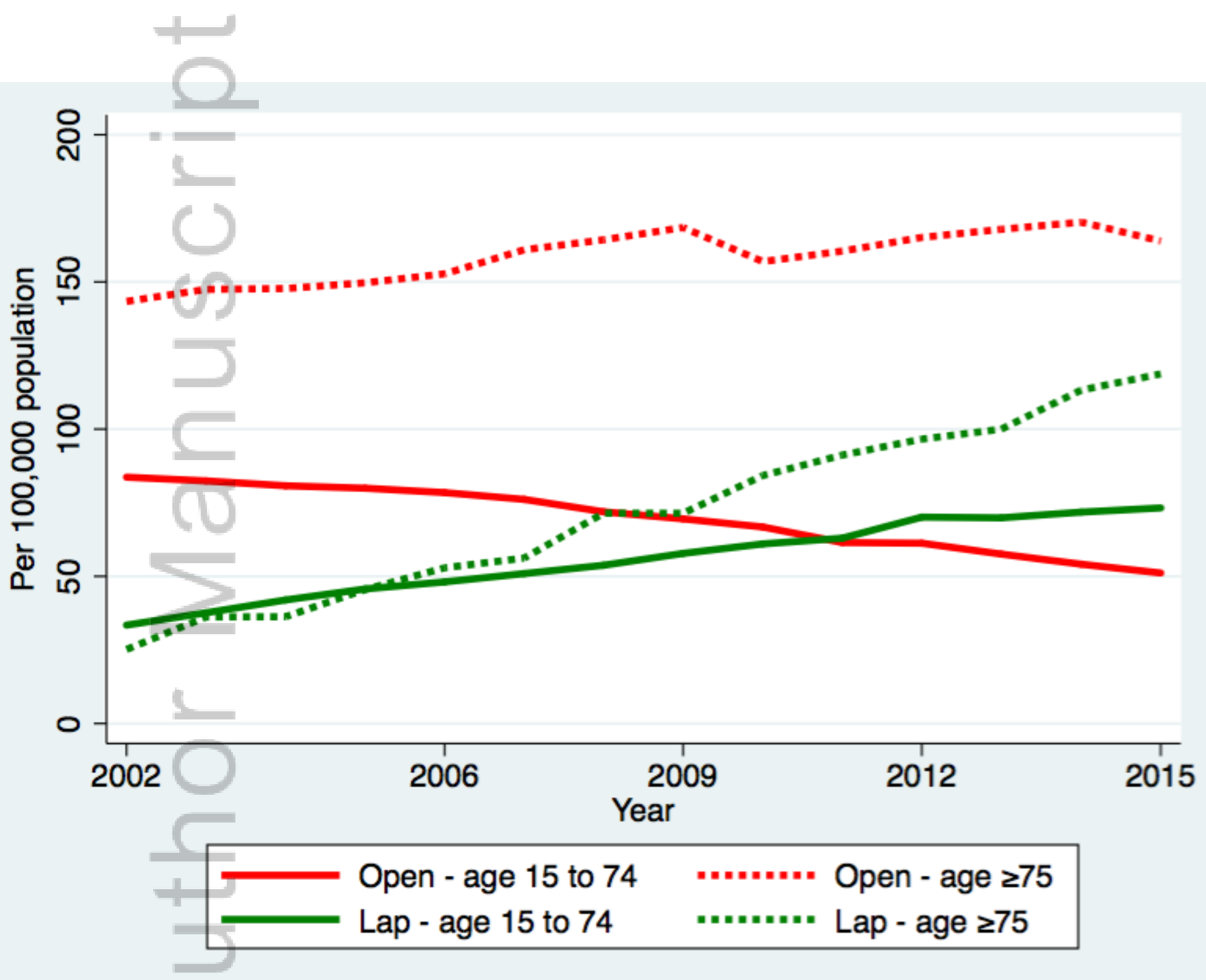

Figure 4. Yearly incidence of hernia surgeries performed, split by surgical approach and stratified by age..tif 


\section{University Library}

\section{- M M N E R VA A gateway to Melbourne's research publications}

Minerva Access is the Institutional Repository of The University of Melbourne

Author/s:

Kevric, J;Papa, N;Toshniwal, S;Perera, M

Title:

Fifteen-year groin hernia trends in Australia: the era of minimally invasive surgeons

Date:

2018-04-01

Citation:

Kevric, J., Papa, N., Toshniwal, S. \& Perera, M. (2018). Fifteen-year groin hernia trends in Australia: the era of minimally invasive surgeons. ANZ JOURNAL OF SURGERY, 88 (4), pp.E298-E302. https://doi.org/10.1111/ans.13899.

Persistent Link:

http://hdl.handle.net/11343/292597 